Article

\title{
When Algorithms Recommend What's New(s): New Dynamics of Decision-Making and Autonomy in Newsgathering
}

\author{
Hannes Cools *, Baldwin Van Gorp and Michaël Opgenhaffen \\ Institute for Media Studies, KU Leuven, Belgium; E-Mails: hannes.cools@kuleuven.be (H.C.), \\ baldwin.vangorp@kuleuven.be (B.V.G.), michael.opgenhaffen@kuleuven.be (M.O.) \\ * Corresponding author
}

Submitted: 16 February 2021 | Accepted: 7 August 2021 | Published: 18 November 2021

\begin{abstract}
Newsroom innovation labs have been created over the last ten years to develop algorithmic news recommenders (ANR) that suggest and summarise what news is. Although these ANRs are still in an early stage and have not yet been implemented in the entire newsroom, they have the potential to change how newsworkers fulfil their daily decisions (gatekeeping) and autonomy in setting the agenda (agenda-setting). First, this study focuses on the new dynamics of the ANR and how it potentially influences the newsworkers' role of gatekeeping within the newsgathering process. Second, this study investigates how the dynamics of an ANR could influence the autonomy of the newsworkers' role as media agenda setters. In order to advance our understanding of the changing dynamics of gatekeeping and agenda-setting in the newsroom, this study conducts expert interviews with 16 members of newsroom innovation labs of The Washington Post, The Wall Street Journal, Der Spiegel, the BBC, and the Bayerische Rundfunk (BR) radio station. The results show that when newsworkers interact with ANRs, they rely on suggestions and summaries to evaluate what is newsworthy, especially when there is a "news peak" (elections, a worldwide pandemic, etc.). With regard to the agenda-setting role, the newsworker still has full autonomy, but the ANR creates a "positive acceleration effect" on how certain topics are put on the agenda.
\end{abstract}

\section{Keywords}

agenda-setting; algorithmic news recommenders; gatekeeping; newsroom innovation labs

\section{Issue}

This article is part of the issue "Algorithmic Systems in the Digital Society" edited by Sanne Kruikemeier (University of Amsterdam, The Netherlands), Sophie Boerman (University of Amsterdam, The Netherlands) and Nadine Bol (Tilburg University, The Netherlands).

(C) 2021 by the authors; licensee Cogitatio (Lisbon, Portugal). This article is licensed under a Creative Commons Attribution 4.0 International License (CC BY).

\section{Introduction}

Newsroom innovation labs have been created over the last ten years to develop algorithmic news recommenders (ANR) that suggest and summarise what news is. With the help of intelligent technologies, these algorithmic recommenders are increasingly being deployed in the news ecosystem, where tools such as Mode (e.g., translating and restructuring stories) and Starfruit (e.g., summarising news stories) are used to make news recommendations based on data (Beam \& Kosicki, 2014; Molumby, 2020; Nechushtai \& Lewis, 2019; Ricci et al., 2011). Due to the newness of these ANRs, it is unclear whether they will create new dynamics or paths for how news reaches the journalist. On the one hand, some point out that these ANRs and recommendations may lead to a decrease in the quality of the news on offer, or result in more polarisation (Helberger, 2019; Pariser, 2011). On the other hand, others point to the positive repercussions of the implementation of such ANRs, as they can result in finding new angles or cause more interaction with readers (Beckett, 2019).

The 2021 Reuters report concludes that three quarters of the editors and CEOs of news outlets surveyed believe that smart technology such as Al will have the most significant impact on journalism in the next five 
years and that this impact will come specifically from news recommender systems (Newman, 2021, p. 30). Although these ANRs are still in an early stage and have not yet been implemented in the entire newsroom, they can create new dynamics within the news ecosystem. By implementing ANRs, these systems have the potential to change both the pace (i.e., the speed of the decision) and the nature (i.e., the choice and selection of relevant articles) of decisions (Bandy \& Diakopoulos, 2020; Pavlik, 2000). Indeed, these systems can result in an intrinsic change of crucial work packages-such as deciding what is new(er)-that are usually carried out by newsworkers. It is essential to focus on the concept of (journalistic) autonomy, a theoretical concept often put forward within the field of human-machine interaction and journalism studies. For example, the use of ANRs can result in a loss of journalistic autonomy in the short term because these ANRs can make decisions more accurately and quickly than newsworkers. In the long term, this may result in a change in core journalistic roles such as gatekeeping and agenda-setting (see, for example, Thurman et al., 2019). In addition, the processes in journalism may also change as a result of this new technological application, as ANRs may influence how and where the news moves and goes.

As Shin (2020) notes, research on the role of newsworkers in relation to these ANRs as potential gatekeepers and agenda setters is somewhat limited. In other words, it is less clear how the news employee interacts with the ANR. That is why in this study we focus on the impact of these ANRs by conducting indepth interviews with newsroom innovation lab employees at The Washington Post, The Wall Street Journal, Der Spiegel, the BBC, and the Bayerische Rundfunk (BR) radio station. These labs are usually part of the overarching newsroom but, unlike the newsroom, they often have a greater affinity with the development and implementation of news tools such as ANRs. The choice to focus on newsroom innovation labs is deliberate, as many of these ANRs are still in a beta phase and are not being used across the newsroom. Lab members-who are, by definition, innovators or at least early adopters-are therefore best placed to assess how these tools are already changing the work and role of the journalist today and how they can and will influence journalism in the near future. By carrying out this study, we want to advance our understanding of the newsworker-ANR interaction, as the issue as to who makes the decisions, selects the news, and sets the digital agenda has become more complex and unclear.

\section{Literature Review}

\subsection{New Actors in the News Ecosystem: Algorithmic News Recommenders}

The emergence of new technologies and digital platforms has created a need within newsrooms to innovate continuously and has led to the existence of newsroom innovation labs (Tameling \& Broersma, 2013; Thurman et al., 2019). With the further development of $A l$ in the form of machine learning and natural language generation, newsrooms can develop and implement tools that support certain workflows of journalists and in some cases, partially take over specific tasks (Diakopoulos, 2020). One of the tools developed in newsroom innovation labs are ANRs, which are gradually leaving the labs and gradually becoming new links within the news production process.

In order to examine the new dynamics being brought about by these ANRs, it is essential to distinguish between four types of recommender systems. Firstly, some systems make personalised recommendations based on metadata (content-based). Secondly, some ANRs obtain insights based on what other users like to read (collaborative filtering). Thirdly, some algorithms work on data about their users (knowledge-based). Finally, there is a type of ANRs that combine the previous algorithms (see, for example, Helberger, 2019; Karimi et al., 2018). For the scope of this study, we will focus solely on content-based ANRs because they are primarily used in the newsgathering phase. What they actually do is make recommendations to the journalist based on articles, press releases, and other data. In this study, we are not talking about news recommendation systems (such as tools like Chartbeat and SmartOcto), which perform tasks like mapping out the reading habits of the public and, based on that data, making suggestions to the journalist as to whether or not a specific article should be given more prominence on a website or in a newsletter.

These ANRs and the way they collect and analyse data have the potential to serve as a tool for newsworkers, as they are able to present recommendations for news articles to journalists, detect breaking news events and make predictions (Beam \& Kosicki, 2014; Diakopoulos, 2019; Marconi, 2020). Due to the novelty of these tools, it is not yet sufficiently clear how these specific ANRs are being used within a news ecosystem, and more specifically, how the newsworker interacts or does not interact with this tool. Since one of the core tasks of media outlets is to provide citizens with accurate information (the so-called watchdog function), it is relevant to investigate whether these ANRs can help or obstruct the newsworker. For example, The Washington Post used an algorithmic recommendation system (content-based) called Lead Locator, which displayed the voting results of specific candidates during the November 2020 presidential election. This tool was developed in their dedicated lab that forms part of the general newsroom and uses machine learning to look for outliers in election data by district (Diakopoulos et al., 2020). In doing so, the algorithm compares the data to previous elections in a given locality and, based on that data, writes a short "tip sheet" that the journalist sees in the Lead Locator tool. Based on the available data, the ANR starts making suggestions about what is newsworthy or what could be a possible 
lead. The tool and its suggestions may therefore cause the way journalists gather, select, and plan their news to be different than before (i.e., without the ANR). As with Lead Locator, other tools have been developed which, using automated writing, make local stories available to reporters, some of which are then used as leads for additional local coverage.

These ANRs can therefore influence the pace of certain decisions that journalists make on a daily basis and the nature of the choices made, such as selecting certain information or data in order to arrive at an article. The newsworker-ANR interaction is therefore a relevant topic of study, as this interaction has the potential to modify the pace and nature of the work of journalists. As part of such a study, it is also essential to focus on the concept of autonomy that is often put forward within human-machine interaction, as it advances our understanding on how technology can impact journalistic autonomy. Autonomy is defined here as the "freedom that a professional has in performing his or her professional tasks" (Reich \& Hanitzsch, 2013, p. 135). As ANRs quietly permeate the news ecosystem newsroom, they have the potential to affect the freedom or autonomy of human newsworkers. Since autonomy has been described as a core value of journalism (Deuze, 2005), this reality could change how autonomy is defined and embedded in the newsroom's daily decision-making. It needs to be rethought in the context of what Splendore (2016, p. 348) called "the increasing intervention of machines." Augmented intervention could mean redefining the autonomy of human newsworkers, as these tools will increasingly take charge of what Diakopoulos (2015, p. 400) called "autonomous decision-making."

This degree of autonomy also relates to McLuhan's (1964) work and is rooted in the theory of technological determinism, a reductionist theory that assumes that a society's technology determines its social structure. Here, the tool used to communicate influences the recipient's mind (Lewis et al., 2019; McLuhan, 1964). In this study, we would therefore like to examine the relationship and interaction between ANRs and newsworkers and evaluate whether these interactions can enhance, or complicate, the performance of their work packages in newsgathering (Milosavljević \& Vobič, 2019). As these ANRs assist newsworkers in suggesting, selecting, and summarising news, they may cause new dynamics to emerge in how newsworkers perform their gatekeeping and agenda-setting roles.

\subsection{New Dynamics of Decision-Making in Gatekeeping}

Nechushtai and Lewis (2019) have pointed out that since the rise of the internet, ANRs can be considered "intervening factors," as they have entered the news ecosystem quite bluntly and influenced the way decisions are made by newsworkers. Indeed, an ANR can help determine which topics to cover and has the potential to influence the news employee's choice about what makes cer- tain information newsworthy. We elaborate on how this gatekeeping role may or may not change if an ANR is able to detect, present, and summarise what news is. After all, if we define gatekeeping as "the process of selecting, writing, editing, posting, scheduling, repeating, and otherwise massaging information to become news" (Shoemaker et al., 2009, p. 73), then it is immediately apparent that the previously described functions of an ANR have a direct link to these journalistic roles and that recommender tools can influence the news production process and the final news output.

Previous studies by Tandoc (2017) and Vu (2014) have demonstrated the impact of metrics tools on editorial choices and pointed to the new dynamics of gatekeeping. Indeed, as these studies have shown, metrics systems (software that links to the news site and indicates, for example, how often an article is clicked on and how long people stay on it on average) can have an impact on news selection and editorial decision making, which can influence news diversity. Algorithmic recommendation systems are also often considered "black boxes," contributing to concerns that news executives will increasingly use them when news outlets are under commercial pressure. This evolution could result in an audience turn, where these recommender systems will be used to distribute personalised content to their online news consumers, leading in some cases to information silos and filter bubbles (Belair-Gagnon \& Holton, 2018; Diakopoulos \& Koliska, 2017). Tandoc and Thomas (2015, p. 247) concluded that because of algorithmic recommender systems, these filter bubbles could lead to "ghettoizing citizens into bundles based on narrow preferences and predilections rather than drawing them into a community."

If we consider these metrics systems, such as Chartbeat and SmartOcto, as influencing news selection, we can argue that ANRs in particular-which can be considered even more sophisticated as metrics systemsmay influence what is "newsworthy." Apart from the abundant research on metrics systems, there has been no research on ANR tools to date, apart from a study by Helberger (2019). She focused on the democratic role of ANRs and argued that these ANRs could create both opportunities and threats when implemented in the news ecosystem. As far as opportunities are concerned, she concluded that ARNs are seen as tools that can reinvent media processes, increase interactivity with readers, and result in news content that is more diverse. As with other algorithmic recommender systems, a potential threat could be the lack of transparency and diversity in disseminating information by those ANRs among journalists and the danger of even greater filter bubbles for online news consumers (Diakopoulos \& Koliska, 2017; Nechushtai \& Lewis, 2019).

According to Diakopoulos (2019), algorithmic recommender systems can act as gatekeepers because they can process information and data by prioritising, classifying, associating, and filtering it. Through automation, they 
can also produce short messages and therefore can suggest or summarise what is newsworthy-think of the "tip sheets" of the Lead Locator-meaning that these ANRs can be seen as even more skilled helpers (or possibly even decision-makers) for the journalist as gatekeepers, compared to the more familiar metrics systems. Since no research has so far been carried out on the interaction between news employees and ANRs, we want to investigate how this interaction takes place within newsgathering. Importantly, we will focus on newsworkers who are members of newsroom innovation labs. These newsworkers are in the cockpit of newsroom innovation and often have different profiles to those of journalists in the broader news ecosystem or newsroom. Because these ANRs are often still in the beta phase, and because the members have a greater affinity with what a tool can and cannot do, they also have a better understanding of how the newsworker-ANR interaction takes place. Because these newsroom innovators are the most knowledgeable about the capabilities, advantages, and disadvantages of these tools, they may also have a better idea of how an ANR might affect a newsworker's daily decisions. This brings us to the first research question: How do members of newsroom innovation labs experience ANRs on the newsworkers' daily decisions in newsgathering?

\subsection{New Dynamics of Autonomy}

ANRs have the potential to change the role of newsworkers as decision-makers and the way they put something on the "media agenda" (Diakopoulos, 2020). In this study, agenda-setting is seen as the process by which mass media determine what we think and care about (McCombs, 2005). It is how news media come to label topics as more important and present them more prominently, with the result that audiences tend to see these topics as more relevant than others. Like gatekeeping, the agenda-setting role of the media has undergone a new dynamic since the rise of the Internet. New potential agenda setters have appeared on the scene, such as the public and tools that can at least control what goes on the agenda (Denham, 2010; Golan, 2006; McCombs, 2004; Wallsten, 2007). With these new potential agenda setters in mind, scholars have long questioned the agendasetting power of traditional media. Studies by Brosius et al. (2019) and Tan and Weaver (2007) have analysed the longitudinal evolution of agenda-setting among media and have pointed to the importance of diffusion of agenda-setting in the digital age. In other words, the traditional way of agenda-setting no longer applies online, and the rise of social media platforms has led to a newer process of agenda-setting.

Research by Gleason (2010) and Tandoc and Eng (2017) has shown that the popularity of platforms such as Twitter and Facebook have changed the process of news gathering and how agenda-setting takes place, with the agenda-setting role of traditional media allegedly becoming more diffuse and complex (Weimann
\& Brosius, 2016). With mass media seemingly struggling to maintain their grip on the public agenda due to increasing selectivity and audience fragmentation, concerns about how news distribution occurs in society have only increased (Feezell, 2018). In short, in a world of ever-evolving digital media, customised news, and fragmentation of online audiences who can choose which news to consume within a high-choice media environment (Van Aelst et al., 2017), it is becoming less and less clear whether a general news agenda still exists and who sets that news agenda.

Therefore, it is essential to look at how ANRs that are developed and implemented to help newsworkers find, select, verify, summarise, and disseminate news can influence the agenda-setting power of news media and journalists. As these ANRs increasingly decide what data and information are shared with newsworkers and assist in the more diffuse and complex process of agendasetting, these ANRs would, at least partially, determine what is put on the agenda by the news media. Since these ANRs are more sophisticated than metrics systems and can suggest and summarise what is news, it is relevant to look at the news employee's self-perceived decision-making power as an agenda setter.

Although many ANRs are still in their infancy and their success or failure is still uncertain, researchers underscore the importance of newsrooms that adopt a strategy about Al, automation, and computational journalistic tools (Beckett, 2019). Because the relationship of newsworkers and computational journalistic tools is relatively new, journalists will have to learn to "share autonomy," as Deuze (2005) puts it. Building on that development, there could come a time when newsworkers consciously need to outsource their decisions to non-human agents. Helberger (2019) points out that it is crucial for the news employee that an ANR does not encroach on his or her autonomy or decision-making freedom, as this could lead to a breach of trust with the news employee. As a result, the lack of guaranteed autonomy may lead the news employee to decisively reject further interaction with the ANR. This brings us to the second research question: How do members of newsroom innovation labs consider the influence of ANR on the autonomy of setting the agenda for newsworkers?

\section{Method}

This qualitative study focuses on newsworkers from American, British, and German newsroom innovation labs, as these labs have been working for some time on one or various ANRs. The respondents were selected using the snowball method and focused on the members of the lab that are familiar with ANRs. The sample consists of 16 members from The Washington Post (4), the BR radio station (2), The Wall Street Journal (2), the BBC (6), and Der Spiegel (2). The average age of our respondents is 34.6, with the youngest being 25 and the oldest 61 . Almost all members of the sample have 
a master's degree and have a background in journalism, computer science, or both.

At the request of some interviewees, we do not mention names in the analyses and use an identifier instead. The interview guide is divided into three parts: During the first part of the questionnaire, we probed for information about the individual news employee, such as job title, background, and responsibilities. In the second part, we focused on their role as gatekeepers and the use of ANR in their daily decision-making in the process of news gathering. The third part of the questionnaire concentrated on how ANRs have a potential impact on the autonomy of the newsworker as an agenda setter. In this series of interviews, the focus is on the interaction with ANRs that are already in use, albeit sometimes still in a beta phase.

A qualitative, descriptive method was used to analyse the interviews (Braun \& Clarke, 2006). The 16 interviews lasted one hour on average and were conducted via Skype because of Covid-19. The recordings were transcribed, and the responses were qualitatively coded and analysed to answer the research questions. Particular attention was paid to the statements around ANRs and the role of gatekeeping and agenda-setting. Our main goal during coding was primarily to identify the different ANRs and the variety of potential impacts they have on gatekeeping and agenda-setting, rather than to make a representative estimate of the ANR's impact on the entire news ecosystem.

\section{Results}

Since we want to map out which ANR are present in the various newsrooms of our sample, and since these ANRs are also related to the results, we will give a brief overview of the ANR here. The BBC uses an ANR called Modus, which helps newsworkers to quickly summarise what is new(s) by displaying the most important highlights of a text or photo in bullet points. At the BR and Der Spiegel, they use the same technology for their ANR as they do at BBC. The Washington Post has different ANRs but, for the scope of this study, we solely focus on the Lead Locator. This ANR is being used for national and regional elections in the US and suggests potential leads based on clean data. The The Wall Street Journal is experimenting with a tool that monitors stock prices and, based on these fluctuations, automatically sends short messages to newsworkers. In this way, newsworkers can be notified more quickly of sudden stock movements. An overview of the results is given below by focusing on both the decision-making and on the autonomy of agenda-setting.

\subsection{Algorithmic News Recommendations and Decision-Making in Newsgathering}

All newsroom innovation lab members see why an ANR is implemented in the newsgathering phase, but some realise that using an ANR in their daily decisions can be useless too. When they were asked how these ANRs can influence a newsworker's decision-making, they highlighted the fact that they use an ANR especially when there is a so-called "news peak" (e.g., an election night, a worldwide pandemic, other breaking news, etc.). In the case of this peak, respondents are more inclined to delegate part of their decision-making to an ANR. The ANR will help determine what kinds of stories and leads will be used in newsgathering and will lead to potential stories in the phase of news production. The interviews show that the respondents see the ANR as a tool that spurs the decision-making process. Respondents point to a certain level of reluctancy when interacting with the ANR initially, as they have no idea what the features were of these ANRs. As they start to interact with the ANR, this results in a more precise delineation of what the tool can and cannot do. Respondents refer to an ANR as a "shovel" or an "assistant" to uncover potential leads or patterns in newsgathering. Other members of newsroom innovation labs underscore that ANRs can free up time in the newsgathering phase:

We use the ANR as a shovel to dig up interesting leads from databases and information flows. In the beginning, I was rather hesitant to use the ANR, but when I started interacting with it, I realised it could optimise the decisions I make. (Respondent 12)

An ANR helped us to cover the riots at the US Capitol as we used several datasets. With the help of this ANR, this journalist went over to three or four editors and said: "Here are the potential storylines we could use....The ANR was definitely good enough to suggest what could be newsworthy. (Respondent 1 )

The process of gatekeeping gets automated or optimised in a way. When journalists interact with ANRs, they will uncover different patterns of what is newsworthy. This will make them more capable of analysing possible leads. The tools could free up time, and the journalists can slow down their newsgathering processes and have a look at where they get their news. (Respondent 16)

When we evaluate the interaction between the newsworker and the ANR in the context of newsgathering, we notice a "trust-distrust dichotomy." In other words, there is a group of respondents who trust ANRs and another group who distrust these tools and how they may impact their decision-making. A group of newsroom innovation lab members points out that newsworkers place great trust in the ANR they use. Without being aware of all the tool's functionalities, they nevertheless start to rely on what the ANR labels as newsworthy and, as one respondent puts it, adopt a kind of "lazy attitude." Respondents in and outside innovation labs place trust in what the tool is selecting, summarising, and suggesting is without 
flaws, as it has been presented as a "smart technology." To inform these newsworkers that have "blind faith" in these ANRs, members of specific innovation labs mention that they add a disclaimer on the ANR platform stating the flaws of these systems:

Some journalists who started using the ANR have become lazy. They think that the algorithm makes no mistakes in summarising or suggesting what news and newsworthy could be. The faith in the tool transcends the criticism of the user. (Respondent 11)

I was a bit surprised by the fact that other journalists would want to know how these ANRs work, but somehow, they do not care....They use the tool to gather the news and only start complaining when certain features do not work sufficiently....We needed to add a disclaimer to the ANR saying that these tools can make mistakes as well. (Respondent 2)

At the same time, there is a group of newsworkers who do not trust the functionalities of an ANR within newsgathering. According to another group of respondents, this distrust is related to a fear that they "will lose their journalistic autonomy or their editorial control." This group does not believe that the technology and the functionalities of an ANR are sufficient enough to suggest what could be newsworthy. Respondents mention that journalists outside the newsroom innovation labs do not have "the right skill set" to work with these ANRs, resulting in a knowledge gap. This means that the innovation lab members are most familiar with the ins and outs of the ANR but that other newsworkers in the ecosystem do not have that same knowledge to use the ANR responsibly:

With respect to one ANR project, the algorithm we tested was not sufficient enough, so members of the lab did not want to develop that ANR further. The suggestions sent out to journalists were not interesting enough in the sense that they were like: "Hey, we should write something about this!" At this point, we do not have the right skillset and enough resources for that. (Respondent 8)

The ANR that we used to suggest what is news is not sufficient enough as the technology for German language models is not advanced today. That is why journalists are not really using it yet....For English, we use the tool to find what could be newsworthy. (Respondent 11)

When we review what can be improved in the ANRnewsworker interaction, one specific leitmotif often recurs: The majority of the respondents point to the importance of the "human in the loop." The members of newsroom innovation labs insist on human control and supervision, even if it turns out that technology in the form of machine learning will ensure that such ANRs will become more complex, advanced, and therefore more autonomous in newsrooms. Some respondents also point out that the lower forms of decisionmaking (e.g., suggesting what might be newsworthy) can be done by a tool, but the final decision of what is newsworthy remains with the newsworker:

With all the technology in the world, we still need humans to fight misinformation and disinformation. We aim to contribute to stories that are more personal in the lab....We may have systems that gather the news and show us what could be relevant, but we still need to put a human touch to the story. Technology is just an extra layer to our reporting. (Respondent 3)

The various labs we created were really there to support the newsroom, to improve the jobs of journalists. If I look at an ANR and a newsworker's interaction, I think that the last one is still in charge.... However, the ANR can really be effective in suggesting what news is. (Respondent 10)

I guess that these ANRs could support the journalist to do the lower forms of decision-making. These tools help the journalist in what is relevant and what could be newsworthy, but the final judgement needs to be made by a journalist. (Respondent 14)

\subsection{Algorithmic News Recommendations and Agenda-Setting}

If we evaluate the role of ANR on the autonomy of the newsworker as an agenda setter, we can conclude that, according to the members of the innovation labs, ANR does have the ability to influence what "goes on the agenda." We conclude from the analysis of the interviews that a "positive acceleration effect" emerged when it came to the agenda-setting process. Since an ANR can summarise, translate, and label news as newsworthy, the pace and nature of the decisions of what topics are chosen can be accelerated. In doing so, respondents say it is crucial to ensure newsworker autonomy. As some innovation lab members point out, within the process of agenda-setting the newsworker is helped by the ANR in the way it presents different topics to them, potentially increasing the diversity of the news. However, the journalist must have full autonomy to write about topic $\mathrm{x}$ or $\mathrm{y}$. If this is not the case, the newsworker will not be inclined to use the ANR:

We have been really conscientious in the lab about what features to include in the ANR and which not. We want to use those tools as amplifiers for our journalists in order to fulfil their function as agenda setter. (Respondent 13) 
Journalists do not want a tool like an ANR that makes decisions for them. They want autonomy and freedom in how they select the topics and how they put these topics on the agenda. If their freedom is not guaranteed, they will not use the ANR. (Respondent 4)

As with daily decision-making, the majority of the respondents pointed to the technological shortcomings of such ANRs, leading to a "trust-distrust relationship." Thus, apart from the full autonomy that newsworkers want to experience during the process of agenda-setting, another reason why certain ANRs are not used is the fact that this tool does not work sufficiently. We see that this "willingness-reluctance attitude" of newsworkers strongly depends on the type of features of the tool and that this attitude also differs from one editorial office to another. In addition, this "trust-reluctance relationship" has its roots in a more considerable tension between the newsroom innovation lab (which knows how the tool works) and the larger, more conservative newsroom (whose staff do not know how this tool works). In light of this, this full autonomy for the newsworker within the process of agenda-setting will not be safeguarded in the future. This evolution is in turn linked to the reduction of distrust in such ANR as the technology will become increasingly sophisticated and complex:

As a lab, we are really isolated from the broader newsroom, and that is also why not a lot of journalists used our ANR system....But here is the key thing: When we augment the newsroom with an ANR, we should be able, at all times, to maintain our editorial control. That will give us the autonomy we need to decide which topics we highlight to our audience. (Respondent 7)

Instead of publishing the news directly produced by an ANR, we have a reporter look at it, supervise it....But in the future, because of technological advancements, journalists will start to trust ANR instead of distrusting it. (Respondent 11)

From the analysis of the interviews, we can infer that the "positive acceleration effect" of ANRs on agenda-setting causes newsworkers to be exposed to more leads, topics, or themes, leading to more news diversity. Respondents speak of "a higher degree of comprehensibility of certain topics," allowing them to make a more informed choice about what to add to the "agenda." Since the algorithm behind these ANRs ensures that specific articles are summarised for the journalist, it is possible for journalists to sift through more information in a short amount of time. Coupled with this, members of the newsroom innovation lab point out that ANRs allow journalists to become better at their jobs:

Because of the suggestions and the summaries of an ANR, I am able to grasp certain stories better. If I read an interesting lead, I will turn to other reporters to ask them if it would be useful to write an article on that. So, in a way, it smoothens the process of me putting certain topics on the agenda. (Respondent 10)

Our core problem is that we have to serve everybody as we have this mandate of universality. So, it is essential to have tools like ANR to do our jobs better. If we have tools to cover stories differently and put issues on the agenda via different platforms, it is useful to have more of these ARS around....Amid a global pandemic, there is a lot of data every day, so then we largely rely on our ARS to make our daily coverage more effective and efficient. (Respondent 7)

Journalism will become more about processing and monitoring information via systems like ANR. Newsworkers will remain the humans in the loop, and they will stay the decision-makers on what to put on the agenda, but the way they weigh their decisions will depend more on ANR and other tools....The news organisations that do not invest in these types of skills and do not train their staff in working with ANR will be left behind. (Respondent 5)

\section{Discussion and Conclusion}

The main goal of this study was to gain a better understanding of how ANRs are used in newsrooms and how they may influence newsworkers' roles as gatekeepers and agenda setters. The interviews with the 16 members of newsroom innovation labs showed that new dynamics do emerge in how newsworkers make their daily decisions (gatekeeping) and that their (journalistic) autonomy changes when they set the digital agenda (agenda-setting).

The results show that ANRs in newsgathering are mainly used during the "news peak" where, in this situation, more decision-making and agency is attributed to the ANR because it can more quickly make different suggestions about what could be newsworthy. These ANRs are therefore seen as a tool that can help the decisionmaking process, a tool that can dig up patterns and recognise them quickly. On the other hand, newsworkers are discovering the limitations of the technology that drives ANRs and have stated that (journalistic) autonomy in the interaction with the tool is all-important. The process of decision-making could be further optimised (in terms of accuracy) and automated (in terms of speed) in the future, but that depends on how much journalists want to grant agency to this ANR. This evolution could give a glimpse of the interaction between newsworkers and ANRs in the future, when specific journalistic roles and work packages will be transformed and partially assigned to a tool thanks to these instruments.

From the analysis of the interviews, we can conclude that ANR does create a new dynamic regarding what is "put on the agenda." For example, the ANR is going to 
make sure that the leads are more diverse, and this may positively affect the role of the journalist as an agenda setter. One of the key results in terms of agenda-setting is the "positive acceleration effect" that ensures that news leads can offer greater diversity with regard to the topics that are put on the agenda. As with gatekeeping, the autonomy of the newsworker in the process of agenda-setting must be maintained. If the ANR is given partial or complete autonomy over the various topics that appear in the newsroom, the newsroom will begin to distrust the ANR and avoid using the tool. The analysis of the interviews shows that news staff do not want to cede their autonomy to the ANR, which immediately points to the fact that using this ANR is an essential requirement when it comes to agenda-setting. Again, the majority of respondents point to a trust-distrust relationship, as in the process of decision making (gatekeeping). This trust-distrust relationship has its roots in a greater tension between the newsroom innovation lab (which knows how ANRs work) and the larger, more conservative newsroom (which does not know how this tool works). On the one hand, there is a group of news staff that trust ANR almost completely, but at the same time has no affinity for how this ANR works on a technical level (i.e., where the data comes from, how the suggestions are formulated).

This trust can lead to a kind of "laziness" on the part of the newsworker, who assumes that the ANR will make few, if any, mistakes in suggesting and summarising what news is. On the other hand, a group of newsworkers outside the innovation labs are starting to avoid interacting with the ANR precisely because of the technical flaws. The fact that those newsworkers encounter bad news leads or summaries may cause them to distrust the ANR. An analysis of the interviews shows that this sense of distrust is strongly associated with a fear of losing control if the newsworker continues to interact with the ANR. This fear is endorsed by members of the innovation labs and can also be related to the argument that there should always be a "person in the loop" who should act as a final gatekeeper. He or she should continue to act as a gatekeeper to assess what can be labelled newsworthy.

This research has limitations. For example, it is questionable whether the views and opinions of members of newsroom innovation labs can be generalised as representative of the views of the entire editorial staff. Previous research has already shown that members of such labs are more tech-savvy and better informed about the different features of tool $x$ or y (see, for example, Beckett, 2019; Tameling \& Broersma, 2013). Therefore, follow-up research could test the differences in views between members of newsroom innovation labs and the broader news ecosystem. This research can start from the concept of autonomy and can therefore advance our understanding of how technology shapes the work processes among newsworkers. In addition, expert interviews have been used to obtain a picture of how this interaction between an ANR on the one hand and a news- worker on the other takes place within various newsroom innovation labs. This method charts the dynamics that occur within specific newsrooms and labs, making the results per news outlet highly context-dependent. Follow-up research could scrutinise a specific newsroom and, through a combination of ethnographic research and expert interviews, examine how such a tool is implemented through the Grounded Theory method (see, for example, Glaser \& Strauss, 2017; Urquhart, 2012). This research could contribute to a better understanding of the use and influence of ANRs on the role of newsworkers, both for journalism scholars and journalism professionals.

\section{Acknowledgments}

We would like to thank the anonymous reviewers for the useful comments that helped us improve the quality of this article.

\section{Conflict of Interests}

The authors declare no conflict of interests.

\section{References}

Bandy, J., \& Diakopoulos, N. (2020). Auditing news curation systems: A case study examining algorithmic and editorial logic in apple news. In M. De Choudhury (Ed.), Proceedings of the fourteenth international AAAl conference on web and social media (pp. 36-47). PKP|PS. https://ojs.aaai.org/index.php/ ICWSM/article/view/7277

Beam, M. A., \& Kosicki, G. M. (2014). Personalized news portals: Filtering systems and increased news exposure. Journalism \& Mass Communication Quarterly, 91(1), 59-77.

Beckett, C. (2019). New powers, new responsibilities. A global survey of journalism and artificial intelligence. Polis LSE. https://blogs.Ise.ac.uk/polis/2019/ 11/18/new-powers-new-responsibilities

Belair-Gagnon, V., \& Holton, A. E. (2018). Boundary work, interloper media, and analytics in newsrooms: An analysis of the roles of web analytics companies in news production. Digital Journalism, 6(4), 492-508.

Braun, V., \& Clarke, V. (2006). Using thematic analysis in psychology. Qualitative Research in Psychology, 3(2), 77-101.

Brosius, H. B., Haim, M., \& Weimann, G. (2019). Diffusion as a future perspective of agenda setting. The Agenda-Setting Journal, 3(2), 123-138.

Denham, B. E. (2010). Toward conceptual consistency in studies of agenda-building processes: A scholarly review. The Review of Communication, 10(4), 306-323.

Deuze, M. (2005). What is journalism? Professional Identity and Ideology of journalists reconsidered. Journalism, 6(4): 442-464. 
Diakopoulos, N. (2015). Algorithmic accountability: Journalistic investigation of computational power structures. Digital Journalism, 3(3), 398-415.

Diakopoulos, N. (2019). Automating the news: How algorithms are rewriting the media. Harvard University Press.

Diakopoulos, N. (2020). Computational news discovery: Towards design considerations for editorial orientation algorithms in journalism. Digital Journalism, 8(7), 945-967.

Diakopoulos, N., Dong, M., \& Bronner, L. (2020, March 20-21). Generating location-based news leads for national politics reporting [Paper presentation]. Computation + Journalism Symposium 2020, Boston, MA, US.

Diakopoulos, N., \& Koliska, M. (2017). Algorithmic transparency in the news media. Digital Journalism, 5(7), 809-828.

Feezell, J. T. (2018). Agenda setting through social media: The importance of incidental news exposure and social filtering in the digital era. Political Research Quarterly, 71(2), 482-494.

Glaser, B. G., \& Strauss, A. L. (2017). Discovery of grounded theory: Strategies for qualitative research. Routledge.

Gleason, S. (2010). Harnessing social media: News outlets are assigning staffers to focus on networking. American Journalism Review, 32(1), 6-8.

Golan, G. (2006). Inter-media agenda setting and global news coverage: Assessing the influence of the New York Times on three network television evening news programs. Journalism Studies, 7(2), 323-333.

Helberger, N. (2019). On the democratic role of news recommenders. Digital Journalism, 7(8), 993-1012.

Karimi, M., Jannach, D., \& Jugovac, M. (2018). News recommender systems-Survey and roads ahead. Information Processing \& Management, 54(6), 1203-1227.

Lewis, S. C., Guzman, A. L., \& Schmidt, T. R. (2019). Automation, journalism, and human-machine communication: Rethinking roles and relationships of humans and machines in news. Digital Journalism, 7(4), 409-427.

Marconi, F. (2020). Newsmakers: Artificial intelligence and the future of journalism. Columbia University Press.

McCombs, M. (2004). Setting the agenda: The mass media and public opinion. Polity.

McCombs, M. (2005). A look at agenda-setting: Past, present and future. Journalism Studies, 6(4), 543-557.

McLuhan, M. (1964). The medium is the message. Routledge.

Milosavljević, M., \& Vobič, I. (2019). Human still in the loop: Editors reconsider the ideals of professional journalism through automation. Digital Journalism, 7(8), 1098-1116.

Molumby, C. (2020, May 20). Modus, semi-automatically creating new story modes. BBC News Labs. https:// bbcnewslabs.co.uk/projects/modus

Nechushtai, E., \& Lewis, S. C. (2019). What kind of news gatekeepers do we want machines to be? Filter bubbles, fragmentation, and the normative dimensions of algorithmic recommendations. Computers in Human Behavior, 90, 298-307.

Newman, N. (2021). Journalism, media and technology trends and predictions 2018. The Reuters Institute. https://reutersinstitute.politics.ox.ac.uk/journalismmedia-and-technology-trends-and-predictions2021

Pariser, E. (2011). The filter bubble: How the new personalized web is changing what we read and how we think. Penguin Press.

Pavlik, J. (2000). The impact of technology on journalism. Journalism Studies, 1(2), 229-237.

Reich, Z., \& Hanitzsch, T. (2013). Determinants of journalists' professional autonomy: Individual and national level factors matter more than organizational ones. Mass Communication and Society, 16(1), 133-156.

Ricci, F., Rokach, L., \& Shapira, B. (2011). Introduction to recommender systems handbook. In F. Ricci, L. Rokach, B. Shapira, \& P. B. Kantor (Eds.), Recommender systems handbook (pp. 1-35). Springer.

Shin, D. (2020). Expanding the role of trust in the experience of algorithmic journalism: User sensemaking of algorithmic heuristics in Korean users. Journalism Practice, 1(2), 1-24.

Shoemaker, P. J., Vos, T. P., \& Reese, S. D. (2009). Journalists as gatekeepers. In K. Wahl-Jorgensen \& T. Hanitzsch (Eds.), The handbook of journalism studies (pp. 73-83). Routledge.

Splendore, S. (2016). Quantitatively oriented forms of journalism and their epistemology. Sociology Compass, 10(5), 343-352.

Tameling, K., \& Broersma, M. (2013). De-converging the newsroom: Strategies for newsroom change and their influence on journalism practice. International Communication Gazette, 75(1), 19-34.

Tan, Y., \& Weaver, D. H. (2007). Agenda-setting effects among the media, the public, and congress, 1946-2004. Journalism \& Mass Communication Quarterly, 84(4), 729-744.

Tandoc, E. C., Jr. (2017). Journalistic autonomy and web analytics. In B. Franklin \& S. Eldridge (Eds.), The Routledge companion to digital journalism studies (pp. 293-301). Routledge.

Tandoc, E. C., Jr., \& Eng, N. (2017). Climate change communication on Facebook, Twitter, Sina Weibo, and other social media platforms. Oxford Research Encyclopedia of Climate Science, 63(6), 1011-1031.

Tandoc, E. C., Jr., \& Thomas, R. J. (2015). The ethics of web analytics: Implications of using audience metrics in news construction. Digital Journalism, 3(2), 243-258.

Thurman, N., Moeller, J., Helberger, N., \& Trilling, D. 
(2019). My friends, editors, algorithms, and I: Examining audience attitudes to news selection. Digital Journalism, 7(4), 447-469.

Urquhart, C. (2012). Grounded theory for qualitative research: A practical guide. SAGE.

Van Aelst, P., Strömbäck, J., Aalberg, T., Esser, F., de Vreese, C., Matthes, J., Hopmann, D., Salgado, S., Hubé, N., Stępińska, A., Papathanassopoulos, S., Berganza, R., Legnante, G., Reinemann, C., Sheafer, T., \& Stanyer, J. (2017). Political communication in a high-choice media environment: A challenge for democracy? Annals of the International Communication Association, 41(1), 3-27.
$\mathrm{Vu}, \mathrm{H} . \mathrm{T}$. (2014). The online audience as gatekeeper: The influence of reader metrics on news editorial selection. Journalism, 15(8), 1094-1110.

Wallsten, K. (2007). Agenda setting and the blogosphere: An analysis of the relationship between mainstream media and political blogs. Review of Policy Research, 24(6), 567-587.

Weimann, G., \& Brosius, H. B. (2016). A new agenda for agenda-setting research in the digital era. In $\mathrm{G}$. Vowe \& P. Henn (Eds.), Political communication in the online world: Theoretical approaches and research designs (pp. 26-44). Routledge.

\section{About the Authors}

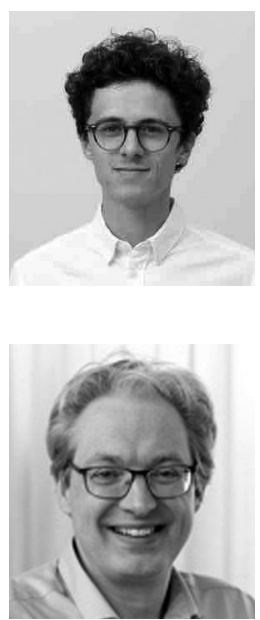

Hannes Cools is a PhD candidate at the Institute for Media Studies, KU Leuven, Belgium. His research interests include computational journalism and news automation.

Baldwin Van Gorp (PhD) is a full professor of journalism and communication management at $\mathrm{KU}$ Leuven, Belgium, where is also the coordinator of the Institute for Media Studies. His research interests include framing, journalism, and the social construction of reality.

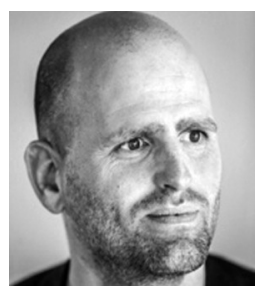

Michaël Opgenhaffen (PhD) is an associate professor at the Institute for Media Studies, KU Leuven, Belgium, where he is also the director of the master's program in journalism. He is visiting professor at the University of Leiden in the Netherlands. His research focuses on the production and consumption of social media news and the future of (digital) journalism. 